\title{
Myelomonocytic leukaemia following cyclophosphamide therapy of rheumatoid disease
}

\author{
RICHARD R. LOVE AND JAMES M. SOWA \\ From the Department of Medicine, Baltimore City Hospitals, and Connective Tissue Division, \\ Johns Hopkins University School of Medicine, Baltimore, Maryland
}

\begin{abstract}
Love, R. R., and Sowa, J. M. (1975). Annals of the Rheumatic Diseases, 34, 534-535. Myelomonocytic leukaemia following cyclophosphamide therapy of rheumatoid disease. A 69-year-old woman treated for 31 months with daily oral cyclophosphamide for refractory rheumatoid disease developed acute myelomonocytic leukaemia $2 \frac{1}{2}$ years after stopping the drug. The possibility of a causal association between the therapy and subsequent leukaemia is supported by the growing experience with cytotoxic agents.
\end{abstract}

The resistance of progressive rheumatoid arthritis to conventional treatments has led to the use of cytotoxic drugs in the therapy of this disease. Controlled trials of cyclophosphamide have shown remarkable improvement and remission of symptoms in patients with severe rheumatoid disease (Fosdick, Parsons, and Hill, 1969; Cooperating Clinics Committee of ARA, 1970; Townes, Sowa, and Shulman, 1972). The risks of therapy with alkylating agents are still undefined in these circumstances and selection of appropriate patients is therefore of foremost concern (Schwartz and Gowans, 1971). At present there are few reports of neoplastic disease occurring in patients with rheumatoid arthritis who were treated with alkylating agents (Fosdick and others, 1969; Cobau, Sheon, and Kirsner, 1973; Tannenbaum and Schur, 1974; Penn, 1974). We report here the development of myelomonocytic leukaemia in a woman $2 \frac{1}{2}$ years after stopping 31 months of treatment of daily oral cyclophosphamide.

\section{Case report}

A 69-year-old black woman was cared for at this institution for over 15 years. She underwent cholecystectomy in 1959, and had had a peptic ulcer since 1963. In 1963 at age 58 years she developed inflammatory arthritis with progression to classic rheumatoid disease. Aspirin (3.6-5.4 g daily), physiotherapy, and intra-articular corticosteroids gave decreasing relief with time. Hydroxychloroquine, begun in March 1965, was discontinued after 4 months because of decreasing visual acuity. Chrysotherapy over the next 3 years, total dose of $3.5 \mathrm{~g}$, gave considerable relief initially; however, the disease became refractory. Because of progressive and incapacitating disease she was considered a suitable candidate for a controlled, double-blind, cross-over study of cyclophosphamide therapy of rheumatoid arthritis (Townes and others, 1972). Beginning in October 1968, she took daily oral cyclophosphamide for 9 months, and the disease activity was markedly reduced. During the subsequent 9-month placebo phase there was recrudescence of her symptoms, and she had to stop work. In May 1970, cyclophosphamide was begun again and was continued until 1972. During 31 months of therapy she usually took $100 \mathrm{mg}$ cyclophosphamide daily. From mid-1972 to mid1974, she was given aspirin and prednisone. Leucopenia and splenomegaly were present from January 1973 onward. In January 1974, keratoconjunctivitis sicca was noted.

Throughout her illness she had anaemia, the degree fluctuating with disease activity. By November 1973, however, the packed cell volume had fallen to $24 \%$. Peripheral blood smear showed considerable aniso- and poikilocytosis, bizarre red cells, occasional nucleated red cells, and large abnormal platelets. Her bone marrow was hypercellular with bizarre immature erythromyelomononuclear cells and megaloblastoid red blood cell precursors. Transfusions were given for symptomatic relief. Acute myelomonocytic leukaemia developed in 
September 1974, with increased white cell immaturity in peripheral blood and bone marrow, falling platelet count, and tender splenomegaly. She died of massive gastrointestinal haemorrhage 12 days after starting leukaemia remission induction therapy with cyclophosphamide, cytosine arabinoside, and vincristine.

\section{Discussion}

The relationship between conventionally treated rheumatoid disease and neoplasia is not close, although Abbott and Lea (1958) have suggested an association between rheumatoid arthritis and leukaemia. Patients with Sjøgren's syndrome are at greater risk of developing malignant lymphoma. Overall, however, there does not appear to be an excess of cancer in patients with rheumatoid disease compared to the general population (Parsons, Strong, and Fosdick 1974). Penn (1974) recorded 46 cancers occurring in 45 patients treated with immunosuppressive drugs for nonmalignant diseases. Six of these patients had rheumatoid arthritis. In these six there were 3 cases of lymphoma and 3 of leukaemia. One leukaemia patient received azathioprine and methotrexate in addition to cyclophosphamide (Cobau and others, 1973).

Fosdick (1974, personal communication) has seen 9 malignancies in over 400 patients with rheumatoid disease treated with cyclophosphamide. There were 5 lymphomas, 1 carcinoma of the bladder, 1 chronic lymphatic leukaemia, 1 stem cell leukaemia, and 1 myelomonocytic leukaemia occurring in a patient treated with both cyclophosphamide and methotrexate. The largest group of patients treated with cytotoxic immunosuppressive drugs for nonmalignant disease is the organ homograft group in whom Penn estimates a 5-6\% incidence of the development of de novo cancers. Thus there is a growing reported experience with cytotoxic immunosuppression which suggests malignancy as a consequence of this therapy. Our patient was one of 21 who completed the cyclophosphamide phase of the drug study. She is the only one to have developed a malignancy.

The dilemma posed by progressive rheumatoid disease requires both physician and patient to weigh the quality of life and the incompletely defined risks of cytotoxic therapy. Among these risks may be the development of cancers.

\section{References}

ABbott, J. D., AND LEA, A. J. (1958) Lancet 2, 880 (Leukaemogens)

Cobau, C. D., Sheon, R. P., AND KirSner, A. A. (1973) Ann. intern. Med., 79, 131 (Letter. Immunosuppressive drugs and acute leukemia)

CoOperating Clinics Committee of American Rheumatism Association (1970) New Engl. J. Med. 283, 883 (A controlled trial of cyclophosphamide in rheumatoid arthritis)

Fosdick, W. M., PARSONS, J. L., AND HILL, D. F. (1969) Arthr. and Rheum., 12, 663 (Abst.) (Long-term cyclophosphamide (CP) therapy in rheumatoid arthritis: a progress report, six years' experience)

Parsons, J. L., Strong, J. S., AND Fosdick, W. M. (1974) J. Rheum., 1, Suppl. 1, 75 (Abst.) (The causes of death in patients with rheumatoid arthritis treated with cytotoxic agents)

Penn, I. (1974) Cancer, 34, Suppl., 858 (Occurrence of cancer in immune deficiencies)

SCHWARTZ, R. S., AND Gowans, J. D. C. (1971) Arthr. and Rheum., 14, 134 (Letter. Guidelines for the use of cytotoxic drugs in rheumatic diseases)

TANNENBAUM, H., AND SCHUR, P. H. (1974) Arthr. and Rheum., 17, 15 (Development of reticulum cell sarcoma during cyclophosphamide therapy)

Townes, A. S., Sowa, J. M., AND Shulmam, L. E. (1972) Arthr. and Rheum., 15, 129 (Abst.) (Controlled trial of cyclophosphamide in rheumatoid arthritis (RA): an 18-month double-blind crossover study) 